\title{
Kajian Kerapatan Tanam dengan Berbagai Arah Baris pada Pertumbuhan dan Hasil Tanaman Sorgum Manis (Sorghum Bicolor (1.) Moench)
}

\author{
Andi Cakra Yusuf ${ }^{1)}$, Roedy Soelistyono ${ }^{2)}$, Sudiarso ${ }^{3)}$ \\ 1) Program Pascasarjana, Fakultas Pertanian Universitas Brawijaya, Jl. Veteran, Malang 65145 \\ 2), 3) Jurusan Budidaya Pertanian, Fakultas Pertanian, Universitas Brawijaya \\ Alamat korespondensi: ${ }^{1)}$ cakrayusuf2@gmail.com
}

\begin{abstract}
ABSTRAK
Perbaikan faktor lingkungan dapat meningkatkan pertumbuhan dan hasil tanaman sorgum manis, salah satu alternatif yang dapat ditempuh dengan memanfaatkan sumberdaya yang telah tersedia. Diantaranya adalah energi radiasi matahari yang berperan dalam proses fotosintesis. Arah baris dan kerapatan populasi tanaman mempengaruhi besarnya energi matahari yang diterima. Sehingga, perlu adanya pengaturan arah baris dan jarak tanam yang tepat agar penerimaan energi radiasi oleh tanaman lebih efisien. Penelitian ini menggunakan Rancangan Acak Petak Terbagi (RPT). Penelitian terdiri dari 2 (dua) faktor perlakuan dan 4 (empat) ulangan. Faktor pertama adalah arah baris timut-barat (TB) dan utara-selatan (US) Sedangkan faktor kedua adalah jarak tanam (JT15, JT30 dan JT45). Hasil penelitian menunjukkan arah baris utara-selatan meningkatkan bobot kering total tanaman umur 53 hst sebesar $\mathbf{3 6 , 7 1 \%}$ apabila dibandingkan dengan arah baris timur-barat. Jarak tanam secara nyata meningkatkan komponen pertumbuhan dan hasil tanaman sorgum manis. Pemberian jarak tanam JT45 memberikan bobot segar total tanaman umur 67 hst dan 81 hst sebesar 35,25\%, namun tidak berbeda nyata dengan JT30. Pemberian jarak tanam JT45 memberikan bobot kering total tanaman umur 81 hst sebesar $11,30 \%$, apabila dibandingkan dengan perlakuan tanam $75 \times 30 \mathrm{~cm}$ dan peningkatan rata-rata sebesar 40,84\% apabila dibandingkan dengan perlakuan jarak tanam 75 x $15 \mathrm{~cm}$. Hasil panen biji kering jarak tanam $75 \times 15 \mathrm{~cm}$ menunjukkan hasil yang lebih tinggi, dimana rata-rata hasil panen biji kering sebesar 3,84 ton $h^{-1}$
\end{abstract}

Kata kunci : kerapatan, arah baris, radiasi.

\section{ABSTRACT}

Improvement of environmental factors could increase the growth and yield of sweet sorghum, one of alternative that could be simply done is by utilizing resources that have been available in environmental. One of them is solar radiation that plays an ultimate role in the process of photosynthesis. We could reach the optimum of solar radiation energy by directing rows and density of plant population. It is true that there is a need for proper arrangement of direction and spacing so that the acceptance of energy by plants is more efficient. This research uses Randomized Plot Design (RPD). The study consisted of 2 (two) treatment factors and 4 (four) replications. The first factor is the direction of the east-west (EW) and north-south (NS) lines while the second factor is the spacing (JT15, JT30 and JT45). The results showed that the north-south row direction increased the total dry weight of 53 dap plant by $36.71 \%$ compared to the east-west row direction. Plant spacing significantly increases the growth component and the result of sweet sorghum plant. JT45 plant spacing gave a total weight of 67 dap and 81 dap for $35.25 \%$, but not significantly different from JT30. JT45 plant spacing gave the total dry weight of 81 dap of $11.30 \%$, equivalent to $75 \times 30 \mathrm{~cm}$ plant treatment and an average increase of $40.84 \%$ compared to $75 \times$ $15 \mathrm{~cm}$ planting. Dry seed yield of $75 \times 15 \mathrm{~cm}$ spacing showed higher yield, where average dry seed yield was 3.84 tons $h^{-1}$.

Keywords: density, row direction, radiation.

\section{PENDAHULUAN}

Produksi gula tahun 2012 sampai 2014 belum mampu memenuhi kebutuhan gula di Indonesia. Data impor pada tahun 2012 sebesar 2.743 .778 ton, tahun 2013 sebesar 3.343.803 ton dan pada tahun 2014 sebesar 2.933.823 ton [1]. Keaadaan tersebut mendorong pengembangan perluasan aneka bahan baku (diversifikasi) agar kondisi rawan pangan dapat dihindari. Sorgum manis merupakan salah satu tanaman pangan yang penting di dunia dan memilki adaptasi luas sehingga dapat ditanam di hampir semua jenis lahan, baik lahan subur maupun di lahan 
marginal. Selain sebagai bahan pangan, sorgum dapat diolah menjadi bahan baku industri gula cair dengan memanfaatkan limbah dari batang sorgum manis. Menurut Haryono [2], sorgum manis mampu menghasilkan biomassa sebesar 80 ton.ha ${ }^{-1}$ per tahun. Potensi biomassa yang tinggi pada sorgum manis melebihi tebu yaitu sebesar 75 ton.ha $^{-1}$. Dalam usaha peningkatan hasil tanaman sorgum manis, perbaikan lingkungan tumbuh tanaman dapat ditempuh dengan memanfaatkan energi yang telah tersedia diantaranya energi radiasi matahari.

Pertumbuhan tanaman dipengaruhi oleh faktor lingkungan seperti energi radiasi matahari. Energi radiasi matahari berperan dalam proses fotosintesis tanaman untuk menghasilkan asimilat yang digunakan dalam pembentukan bagian - bagian tanaman. Oleh karena itu, produksi biomassa merupakan akumulasi dari radiasi matahari selama priode waktu tertentu. Bobot kering tanaman tergantung pada jumlah radiasi yang diintersepsi selama pertumbuhannya. Dalam pertanaman tingkat intersepsi cahaya ditentukan oleh sebaran daun dalam tajuk. Menurut Sitompul [3] radiasi matahari yang diintersepsi dalam tajuk tanaman dapat ditaksir dari selisih antara radiasi yang sampai pada permukaan atas tajuk tanaman dengan radiasi yang berpenetrasi hingga di bawah tajuk atau permukaan tanah. Dalam upaya meningkatkan efesiensi radiasi pada tanaman sorgum manis dapat ditempuh dengan cara pengaturan populasi dan arah baris tanaman.

Arah baris tanam dan kerapatan populasi tanaman mempengaruhi besarnya energi matahari yang diterima. Menurut Sugito [4], peningkatan efesiensi energi radiasi dapat dilakukan dengan cara mengoptimalkan tingkat populasi tanaman, pengaturan sistem bertanam dan pemilihan tipe daun tegak. Arah baris tanam yang searah dengan datangnya sinar matahari dengan jarak tanam lebar, akan terdapat ruang kosong yang mengakibatkan adanya energi radiasi yang tidak digunakan tanaman. Sehingga, perlu adanya pengaturan jarak tanam dan arah baris yang tepat agar penerimaan energi radiasi oleh tanaman lebih efisien.

Kebutuhan radiasi matahari akan berbeda beda tergantung pada jenis tanaman berdasarkan hasil analisis Monteith (1997) dalam [5]. Kiniry et al., (1989) dalam [6] menyatakan bahwa nilai efesiensi penggunaan radiasi matahari pada tanaman jagung sebesar 1,6 $\mathrm{g} \mathrm{MJ}^{-1}$, sorgum 1,3 $\mathrm{g} \mathrm{MJ}^{-1}$, padi dan gandum sebesar $1,0 \mathrm{~g} \mathrm{MJ}^{-1}$. Tanaman sorgum manis merupakan salah satu jenis tanaman $\mathrm{C} 4$ yang sangat efisien dalam memanfaatkan energi radiasi matahari bagi pertumbuhannya. Dengan kemampuan laju fotosintesis yang tinggi, sorgum manis mampu meningkatkan pertumbuhan dan produksi seiring dengan tersedianya energi radiasi matahari yang melimpah.

Tujuan penelitian ini yaitu untuk menentukan arah baris tanaman dan tingkat kerapatan tanaman sorgum manis yang tepat untuk budidaya tanaman sorgum manis sehingga diperoleh hasil yang tinggi.

\section{METODE PENELITIAN}

\section{Tempat dan Waktu}

Penelitian telah dilaksanakan pada bulan November 2016 - Maret 2017 di Kebun Percobaan Universitas Brawijaya, Desa Jatikerto, Kec. Kromengan, Kabupaten Malang. Lokasi terletak 112,27-112,32 ${ }^{0} \mathrm{BT}$ dan 8,08-8,05 ${ }^{0} \mathrm{LS}$ pada ketinggian lebih dari $303 \mathrm{mdpl}$, dengan curah hujan rata-raa antara $100-1600 \mathrm{~mm}$ setiap tahunnya dengan rerata suhu 16 sampai 31 ${ }^{0} \mathrm{C}$.

\section{Rancangan Percobaan}

Rancangan perlakuan yang digunakan dalam penelitian ini adalah petak terpisah (RPT) dan diulang 4 kali. Terdiri dari 2 macam, yaitu :

Petak Utama: Arah baris terdiri dari 2 macam, yaitu :

$$
\begin{aligned}
\text { TB } & =\text { Arah Timur }- \text { Barat } \\
\text { US } & =\text { Arah Utara }- \text { Selatan }
\end{aligned}
$$

Anak Petak : Jarak Tanam terdiri dari 3 macam, yaitu :

$$
\begin{aligned}
\text { JT15 }= & \text { Populasi } 88.889 \mathrm{Ha}^{-1}(\text { Jarak Tanam } \\
& 75 \text { X } 15 \mathrm{~cm}) \\
\text { JT30 }= & \text { Populasi } 44.444 \mathrm{Ha}^{-1} \quad(\text { Jarak Tanam } \\
& 75 \text { X } 30 \mathrm{~cm}) \\
\text { JT45 }= & \text { Populasi } 29.629 \mathrm{Ha}^{-1} \quad(\text { Jarak Tanam } \\
& 75 \text { X } 45 \mathrm{~cm})
\end{aligned}
$$

\section{Tahapan Penelitian}

Tahapan penelitian meliputi persiapan lahan, pengaturan petak, pengaturan jarak tanam, pemupukan, penanaman, pemeliharaan dan panen.

\section{Pengamatan}

Pengamatan dilakukan secara destruktif saat tanaman berumur $25 \mathrm{Hst}, 39 \mathrm{Hst}, 53 \mathrm{Hst}, 67 \mathrm{Hst}$ dan 81 Hst saat panen. Parameter yang diamati dalam pengamatan pertumbuhan meliputi bobot segar total tanaman dan bobot kering total 
tanaman. Parameter yang diamati dalam pengamatan hasil meliputi bobot biji per tanaman, bobot 1000 biji, hasil panen per hektar dan indeks panen.

\section{Analisis Data}

Data pengamatan yang diperoleh kemudian dianalisis dengan menggunakan analisis ragam (uji F) pada taraf 5\% untuk mengetahui ada tidaknya interaksi atau pengaruh nyata dari perlakuan. Apabila terdapat interaksi atau pengaruh nyata maka dilanjutkan dengan uji BNT 5\%, untuk mengetahui perbedaan diantara perlakuan.

\section{HASIL DAN PEMBAHASAN}

Tabel 1. Rata-rata Bobot Segar Total Tanaman Akibat Perlakuan Arah Baris dan Jarak Tanam pada Berbagai Umur Tanaman

\begin{tabular}{|c|c|c|c|c|c|c|c|}
\hline \multirow{2}{*}{ Perlakuan } & \multicolumn{7}{|c|}{ Bobot Segar Total Tanaman (g) pada Umur (hst) } \\
\hline & 25 & 39 & 53 & 67 & & 81 & \\
\hline \multicolumn{8}{|l|}{ Arah baris } \\
\hline TB & 7.00 & 108.70 & 557.03 & 1400.67 & & 1712.29 & \\
\hline us & 7.29 & 93.31 & 680.84 & 1366.54 & & 1663.14 & \\
\hline BNT $5 \%$ & tn & tn & tn & tn & & tn & \\
\hline \multicolumn{8}{|c|}{ Jarak tanam $(\mathrm{cm})$} \\
\hline JT15 & 8.14 & 116.09 & 625.78 & 1076.36 & a & 1429.34 & a \\
\hline JT30 & 7.23 & 89.27 & 693.16 & 1557.11 & b & 1800.34 & b \\
\hline JT45 & 6.07 & 97.66 & 537.86 & 1517.33 & b & 1933.46 & $\mathrm{~b}$ \\
\hline BNT $5 \%$ & tn & tn & th & 210.04 & & 241.05 & \\
\hline
\end{tabular}

Tabel 2. Rata-rata Bobot Kering Total Tanaman Akibat Perlakuan Arah Baris dan Jarak Tanam pada Berbagai Umur Tanaman

\begin{tabular}{|c|c|c|c|c|c|c|c|}
\hline \multirow{2}{*}{ Perlakuan } & \multicolumn{7}{|c|}{ Bobot Kering (g) pada Umur (hst) } \\
\hline & 25 & 39 & 53 & & 67 & 81 & \\
\hline \multicolumn{8}{|l|}{ Arah Baris } \\
\hline TB & 1.23 & 3.74 & 89.81 & a & 256.71 & 462.13 & \\
\hline us & 1.27 & 3.51 & 122.78 & b & 245.36 & 447.20 & \\
\hline BNT $5 \%$ & tn & tn & 21.29 & & tn & tn & \\
\hline \multicolumn{8}{|c|}{ Jarak Tanam $(\mathrm{cm})$} \\
\hline JT15 & 1.31 & 3.91 & 104.17 & & 207.73 & 371.28 & $\mathbf{a}$ \\
\hline गT30 & 1.25 & 3.42 & 110.62 & & 280.95 & 469.79 & b \\
\hline JT45 & 1.20 & 3.55 & 104.09 & & 264.43 & 522.92 & c \\
\hline BNT $5 \%$ & tn & tn & tn & & tn & 49.79 & \\
\hline
\end{tabular}

Berdasarkan hasil pengamatan pada peubah bobot segar total tanaman (Tabel 1) terdapat kecenderungan bahwa perlakuan jarak tanam 75 x $45 \mathrm{~cm}$ memberikan pengaruh terhadap bobot segar total tanaman pada saat tanaman tersebut mencapai umur 67 dan 81 hst. Namun tidak memberikan pengaruh yang nyata pada jarak tanam $75 \times 30 \mathrm{~cm}$. Sedangkan pada pengamatan bobot kering total tanaman (Tabel 2) berpengaruh nyata saat memasuki umur 81 hst. Pada perlakuan jarak tanam 75 x $45 \mathrm{~cm}$ menghasilkan rata-rata bobot segar total tanaman yang lebih tinggi apabila dibandingkan dengan pelakuan jarak tanam $75 \times 15 \mathrm{~cm}$ maupun $75 \times$ $30 \mathrm{~cm}$.

Perbedaan hasil bobot segar total tanaman dan bobot kering total tanaman menunjukkan bahwa walaupun memiliki suatu hubungan yang linier, namun kandungan bahan air tanaman dapat berbeda antara tanaman atau bagian tanaman akibat perbedaan lingkungan tumbuh. Jarak tanam yang lebar memberikan hasil fotosintat lebih besar dibandingkan dengan jarak tanam yang lebih rapat. Fotosintesis akan memproduksi asimilat yang diakumulasikan dalam bentuk bahan kering tanaman [5]. Oleh karena itu, Produksi bahan bobot kering total tanaman memiliki hubungan yang positif dengan laju fotosintesis tanaman. Semakin tinggi laju fotosintesis, maka asimilat yang dihasilkan juga semakin tinggi, yang pada akhirnya dapat meningkatkan bobot kering total tanaman.

Tabel 3. Rata-Rata Bobot Biji per Tanaman, Bobot 1000 Biji dan Hasil Panen Akibat Perlakuan Arah Baris dan Jarak Tanam

\begin{tabular}{|c|c|c|c|}
\hline Perlakuan & $\begin{array}{l}\text { Bobot Biij per Tanaman } \\
\qquad(\mathrm{g})\end{array}$ & $\begin{array}{c}\text { Bobot } 1000 \text { Biji } \\
\text { (g) }\end{array}$ & $\begin{array}{l}\text { Hasil Panen } \\
\text { (Ton h) }\end{array}$ \\
\hline \multicolumn{4}{|l|}{ Arah Baris } \\
\hline TB & 48.35 & 23.33 & 2.42 \\
\hline US & 49.33 & 22.00 & 2.63 \\
\hline BNT $5 \%$ & tn & tn & tn \\
\hline \multicolumn{4}{|c|}{ Jarak Tanam $(\mathrm{cm})$} \\
\hline JT15 & $43.27 a$ & 23.50 & $3.84 \mathrm{~b}$ \\
\hline JT30 & $45.49 \mathrm{a}$ & 22.63 & $2.02 \mathrm{a}$ \\
\hline JT45 & $57.75 b$ & 21.88 & $1.71 \mathrm{a}$ \\
\hline BNT $5 \%$ & 4.13 & tn & 0.47 \\
\hline
\end{tabular}

Hasil pengamatan bobot biji per tanaman (Tabel 3) jarak tanam $75 \times 45 \mathrm{~cm}$, menghasilkan rata-rata bobot biji per tanaman yang lebih tinggi apabila dibandingkan dengan jarak tanam $75 \mathrm{x}$ $30 \mathrm{~cm}$ maupun $75 \times 15 \mathrm{~cm}$, namun tidak menunjukkan pengaruh yang nyata pada bobot 1000 biji. Jarak tanam yang renggang pada tanaman sorgum manis akan menghasilkan bobot biji per tanaman yang tinggi, akibat dari kondisi lingkungan yang optimum. Sedangkan pada pengamatan bobot 1000 biji (Tabel 3) tidak terjadi perbedaan yang nyata. Hal ini disebabkan karena faktor genetik dari tanaman tersebut. Bobot 1000 butir merupakan sifat yang stabil dan tidak dipengaruhi oleh faktor lingkungan. Pada parameter hasil panen menunjukkan bahwa perlakuan jarak tanam tanam $75 \times 15 \mathrm{~cm}$ menghasilkan rata-rata hasil panen (Tabel 3) yang lebih tinggi apabila dibandingkan dengan 
jarak tanam $75 \times 30 \mathrm{~cm}$ dan $75 \times 45 \mathrm{~cm}$. Hal tersebut mengindikasikan bahwa pada jarak tanam $75 \times 15 \mathrm{~cm}$ masih efesien untuk produksi sorgum manis disebabkan sifat biji yang stabil dan tidak dipengaruhi oleh faktor lingkungan. Meskipun ukuran malai kecil akan tetapi populasi tanaman lebih banyak sehingga hasil panen lebih tinggi.

Tabel 4. Rata-rata Indeks Panen Akibat Perlakuan Arah Baris dan Jarak Tanam

\begin{tabular}{lc}
\hline \multicolumn{1}{c}{ Perlakuan } & Indeks Panen $\left(\mathrm{t}^{-{ }^{-1}}\right)$ \\
\hline Arah Baris & 0.03 \\
TB & 0.03 \\
US & tn \\
\hline BNT 5\% & 0.01 a \\
\hline Jarak Tanam (cm) & 0.03 b \\
JT15 & $0.04 \mathrm{~b}$ \\
JT30 & 0.01 \\
JT45 & \\
\hline BNT 5\% &
\end{tabular}

Berdasarkan hasil pengamatan peubah Indeks panen (Tabel 4) perlakuan jarak tanam $75 \times 45$ $\mathrm{cm}$ memberikan perbedaan yang nyata terhadap peubah Indeks panen. Perlakuan jarak tanam 75 x $45 \mathrm{~cm}$ menghasilkan rata-rata indeks panen yang lebih tinggi apabila dibandingkan dengan jarak tanam $75 \times 15 \mathrm{~cm}$. Namun tidak terjadi perbedaan yang nyata apabila dibandingkan dengan dengan jarak tanam $75 \times 30 \mathrm{~cm}$. Pada dasarnya peningkatan nilai indeks panen berbanding lurus dengan populasi tanaman. Populasi yang lebih sedikit menghasilkan bobot biji yang lebih tinggi pada brangkasan yang sama. Pada bobot kering brangkasan tersebut terdiri dari bobot kering tajuk. Pada jarak tanam yang lebar dengan populasi sedikit menghasilkan tajuk yang lebih besar. Tajuk, seperti halnya daun merupakan organ yang berperan dalam menghasilkan fotosintat melalui proses fotosintesis. Sedangkan malai dan biji termasuk lubuk yaitu pengguna fotosintat. Besar kecilnya lubuk yang dihasilkan oleh tanaman akan sangat bergantung pada besarnya kecilnya sumber [7].

\section{KESIMPULAN}

\section{Kesimpulan}

1. Jarak tanam $75 \times 45 \mathrm{~cm}$, memberikan peningkatan rata-rata bobot segar total tanaman sebesar $35,25 \%$ apabila dibandingkan dengan jarak tanam $75 \times 15$ $\mathrm{cm}$. Namun tidak berbeda nyata pada jarak tanam $75 \times 30 \mathrm{~cm}$, dimana selisih peningkatan hanya sebesar 7,3\%.
2. Jarak tanam $75 \times 45 \mathrm{~cm}$, memberikan peningkatan rata-rata bobot kering total tanaman sebesar $\quad 40,84 \% \quad$ apabila dibandingkan dengan jarak tanam $75 \times 15$ $\mathrm{cm}$. Ada peningkatan rata-rata bobot kering total tanaman sebesar $11,30 \%$ apabila dibandingkan dengan jarak tanam 75 x 30 $\mathrm{cm}$. Perlakuan arah baris utara - selatan (US) menghasilkan peningkatan rata-rata bobot kering total tanaman sebesar 36,71\% apabila dibandingkan dengan perlakuan arah baris timur - barat (TB).

3. Hasil panen biji kering jarak tanam $75 \times 15$ $\mathrm{cm}$ menunjukkan hasil yang lebih tinggi, dimana rata-rata hasil panen biji kering sebesar 3,84 ton $\mathrm{h}^{-1}$.

\section{DAFTAR PUSTAKA}

[1] Badan pusat statistik. 2014. Data Badan Statistik Tentang Perkembangan Impor Gula dan Tetes Tebu Indonesia. https://w ww. Bps.go.id/website/pdfpublikasiStatistikTebu-Indonesia.

[2] Haryono. 2013. Dukungan Badan dan Litbang Menuju Pertanian Bioindustri. In: Prosiding Seminar Nasional Serealia. Maros, 18 Juni 2013 Pp.1 - 10.

[3] Sitompul, M. 2016. Analisis Pertumbuhan Tanaman. Fakultas Pertanian Brawijaya Malang.

[4] Sugito, Y. 2012. Ekologi Tanaman. Fakultas Pertanian Universitas Brawijaya Malang.

[5] Gardner, L. P., R. B. Pearce and R. L. Mitchell. 2003. Physiology of Crop Plants. Lowa State University Press. United States. $11-12$.

[6] Abdullah, h. 2010. Efesiensi Konversi Energi Radiasi Matahari Tiga Varietas Pado (Oryza sativa L.) Pada Kepadatan Tanaman Yang Berbeda. Tesis Program Ilmu Tanaman Minat Agronomi. Program Pasca Sarjana Universitas Brawijaya.

[7] Kiswanto, D. Indradewa dan E. T. S. Putra. 2012. Pertumbuhan dan Hasil Tanaman Jagung (Zea mays L.), kacang tanah (Arachis hypogaea $\mathrm{L}$ ) dan jahe (Zingiber officianale var. officianale) Pada Sistem Agroforestri Jati di Zona Ledok Wonosari, Gunung Kidul. J. Pertanian. 2 (2) : $36-46$. 